\title{
Absolutely continuous and pure point spectra of discrete operators with sparse potentials
}

S. Molchanov ${ }^{1}$, O. Safronov ${ }^{1}$, and B. Vainberg ${ }^{1}$

${ }^{1}$ UNC Charlotte

December 17, 2021

\begin{abstract}
We consider the discrete Schr $\backslash$ " odinger operator $\$ \mathrm{H}=-\backslash$ Delta $+\mathrm{V} \$$ with a sparse potential $\$ \mathrm{~V} \$$ and find conditions guaranteeing either existence of wave operators for the pair $\$ \mathrm{H} \$$ and $\$ \mathrm{H}_{-} 0=-\backslash$ Delta $\$$, or presence of dense purely point spectrum of the operator $\$ \mathrm{H} \$$ on some interval $\$[\backslash$ lambda_0,0]\$ with $\$ \backslash$ lambda_0 $<0 \$$.
\end{abstract}

\section{Hosted file}

SparseScattering2Arxiv.pdf available at https://authorea.com/users/451626/articles/549853absolutely-continuous-and-pure-point-spectra-of-discrete-operators-with-sparsepotentials

\section{Hosted file}

SparseScattering2Arxiv.tex available at https://authorea.com/users/451626/articles/549853absolutely-continuous-and-pure-point-spectra-of-discrete-operators-with-sparsepotentials 